\title{
Effect of functional electrical stimulation versus TheraTogs on gait and balance in children with hemiplegic cerebral palsy: a randomized controlled trial
}

\author{
Shamekh Mohamed El-Shamy* (1) and Ehab Mohamed Abd El Kafy
}

\begin{abstract}
Background: Children with cerebral palsy exhibit postural restrictions and gait problems as a result of both primary and secondary brain damage impairments. One of the main goals of cerebral palsy rehabilitation is to improve gait and balance. As a result, the purpose of this study was to compare the effects of FES and TheraTogs on gait and balance in children with hemiplegic CP. A randomized controlled study was conducted on 30 children with hemiplegic CP (18 boys and 12 girls) between the ages of 8 and 12 years. The children were divided into two equal groups. In addition to the traditional physical treatment program, the FES group received functional electrical stimulation (pulse width $300 \mu$ s, frequency $33 \mathrm{~Hz}, 2 \mathrm{~h} /$ day, 3 days/week, 3 months). The TheraTogs group, on the other hand, received the TheraTogs strapping system as well as the same traditional program for the same time period. The 3-D motion analysis and the Biodex balance system were used to analyze gait parameters and postural stability at baseline and 3 months after the intervention.
\end{abstract}

Results: When comparing the mean values of the gait parameters and postural stability indices of children in both groups before and after treatment, a significant improvement was reported. Furthermore, the FES group showed a greater improvement in all of the measured outcomes $(P<0.001)$.

Conclusion: Functional electrical stimulation improves gait pattern and postural stability in children with hemiplegic cerebral palsy significantly more than TheraTogs strapping systems.

Clinical trial registration: This study was registered in the ClinicalTrial.gov PRS (NCT05020834).

Keywords: Cerebral palsy, Hemiplegia, Functional electrical stimulation, TheraTogs, Gait, Balance

\section{Background}

Cerebral palsy (CP) is a term used to describe a group of permanent movement and posture impairments caused by non-progressive brain disorders [1]. Hemiplegia is characterized by the involvement of both the upper and lower limbs on the ipsilateral side, with the upper limb being more severely affected [2]. Hemiplegic CP accounts

\footnotetext{
*Correspondence: smshamy@uqu.edu.sa

Department of Physical Therapy, Faculty of Applied Medical Sciences, Umm Al-Qura University, Makkah, Saudi Arabia
}

for $22.6-40 \%$ of all cases of CP, resulting in decreased functional independence and quality of life [3].

The most common gait impediment for children with hemiplegic $\mathrm{CP}$ is poor foot clearance during the swing phase and diminished heel strike on the affected side, possibly limiting higher-level ambulation and balance skills [4]. Children with hemiplegic CP experience higher energy cost [5] and reduced walking endurance [6] compared to typically developing children.

Children with hemiplegic CP learn to walk with their feet wide apart, knees stiff, and feet turned inwards, 
bearing their weight on the medial portions of their feet. They exhibit impaired balance, visual motor control, and strength, as well as shorter step and stride lengths, a high cadence, and a slow velocity [7]. In ambulatory children with $\mathrm{CP}$, the ankle joint is the most commonly affected joint [8]. Common impairments are insufficient ankle dorsiflexion during swing phase of gait, or foot drop, and excessive plantarflexion during early to mid-stance. Standing and walking instabilities, as well as a higher risk of falling, are possible consequences of these impairments [9].

Pharmacological treatments such as botulinum toxin type A [10], along with a variety of physiotherapy treatments and/or the prescription of ankle foot orthoses (AFOs) are currently being used to help children with hemiplegic CP improve their gait [11]. Although AFOs improve ankle kinematics and temporal-spatial parameters during gait [12], the external support of AFO may hinder balance strategies for secondary repertoire expansion as well as impede power generation for effective push off during walking and running for high functioning children [13]. As a result, research into alternative interventions is warranted.

Functional electrical stimulation (FES) is another treatment that involves surface electrical stimulation of muscles with impaired motor control in order to overcome an inability to contract and execute functional movements [14]. Previous studies of FES to improve ankle function in children with CP [15-17] have reported beneficial effects in gait including improved dorsiflexion, improved gait speed, and reduced asymmetry. However, a large concern has been children's tolerance to wearing devices during normal daily activities [18].

The use of TheraTogs orthotic garments has been suggested to improve the ability to stabilize the posture, to correct or prevent deformities, to improve functionality, and to enable the user a more appropriate functional pattern [19]. A recent clinical trial has shown that the gait pattern of the children with $\mathrm{CP}$ wearing the TheraTogs was significantly improved compared to those who did not wear the TheraTogs [20].

Although the literature suggests that FES and TheraTogs are effective in the treatment of CP [16-20], there is limited research comparing the two therapies. The purpose of this study was to compare the effects of FES and TheraTogs on the treatment of children with hemiplegic CP.

\section{Methods}

\section{Design}

The Ethics Committee of the Umm Al-Qura University approved this randomized controlled trial (HAPO02-K-012-2020-12-516). Parents have completed a consent form allowing their children to participate in the research. The children who participated were chosen from the Physical Therapy Department, Maternity and Children Hospital, Makkah, Saudi Arabia. This trial was registered in ClinicalTrial.gov PRS No. NCT05020834.

\section{Participants, therapists, and centers}

To evaluate age, diagnosis, and inclusion and exclusion criteria, forty children with hemiplegic $\mathrm{CP}$ were first examined and assessed. The following were the criteria for inclusion: magnetic resonance imaging (MRI) was used to confirm the diagnosis of hemiplegic CP in the children who participated in this study. Both sexes are between the ages of 8 and 12. The level of spasticity in the lower limbs ranged from grade 1 to grade 2 on the modified Ashworth scale (MAS). The levels of motor function were between levels I and II, according to the Gross Motor Function Classification System (GMFCS). The children in concern were cognitively capable of comprehending and following directions. They had no major medical issues, according to their medical report. Skin diseases and allergic reactions to the adhesive tape used in this study were excluded, as were any deformities that interfered with lower limb functions, children with pacemakers who were contraindicated by electrical stimulation, children with visual, auditory, or perceptual deficits, children with seizures, and children who had received botulinum toxin or other spasticity medication. Demographic (i.e., age and sex) and clinical (i.e., side of hemiplegia and GMFCS levels) information was collected in order to describe the sample. Therapists were included in the study once they were familiar with the FES and TheraTogs. Centers were included in the study if they were well equipped and specialized in pediatric rehabilitation.

\section{Randomization}

Thirty children with hemiplegic CP met the above-mentioned criteria after the screening process. Children were randomly allocated, using a random number generator, with the allocation to either the FES or TheraTogs group being concealed. The random numbers were generated by the receptionist with every alternate number being marked either 1 or 2 . However, the receptionist was blinded to the interventions assigned to group 1 (FES group) and group 2 (TheraTogs group). During allocation, every subject was asked to pick up one enclosed envelope from a box containing numbers from 1 to 30 . Depending on the number picked by the subject, they were allocated to either group 1 or group 2 by the receptionist. Therefore, two groups of 15 patients each were created with an aim to minimize the risk of allocation bias. All the patients were evaluated at baseline and after 3 months of treatment by the same therapist, who was blinded to 
the allocation of patients to the FES or TheraTogs group. Group 1 (FES group) received traditional physical treatment as well as FES, while group 2 (TheraTogs group) received TheraTogs as well as traditional physical therapy. The experimental design of this study is shown in Fig. 1.

\section{Gait parameters evaluation}

The same examiner used the Pro-Reflex motion analysis (Qualisys; Qualisys Inc., Goeteborg, Sweden) to analyze all children's gait parameters before treatment and after 3 months of treatment. An 8-m-long wooden walkway, a three-dimensional infrared camera system with six cameras evenly positioned on both sides of the walkway, and a personal computer with Q-Trace software installed to analyze the motion pattern comprise this system. Reflective markers with a diameter of $9 \mathrm{~mm}$ are included in this system to help users fine-tune the camera's focus settings.
The superior border of the patella, laterally at the knee joint line, tibial tuberosity, lateral malleolus, heel posterior to the calcaneus, and between the second and third metatarsal heads were all marked bilaterally. The calibration, data capture, and analysis procedures were carried out in accordance with the motion system's manual. Velocity $(\mathrm{m} / \mathrm{s})$, stride length $(\mathrm{m})$, cadence (steps $/ \mathrm{min})$, cycle time (s), and percent of time spent in stance of the affected limb (\%) were the gait parameters that were analyzed [21, 22].

\section{Postural stability evaluation}

The same examiner, who was blinded to the children's assignment, tested all of the children for postural stability before therapy (pre-treatment) and after 3 months of treatment (post-treatment). The Biodex balance system (Balance System SD, Shirely, NY) was used to assess

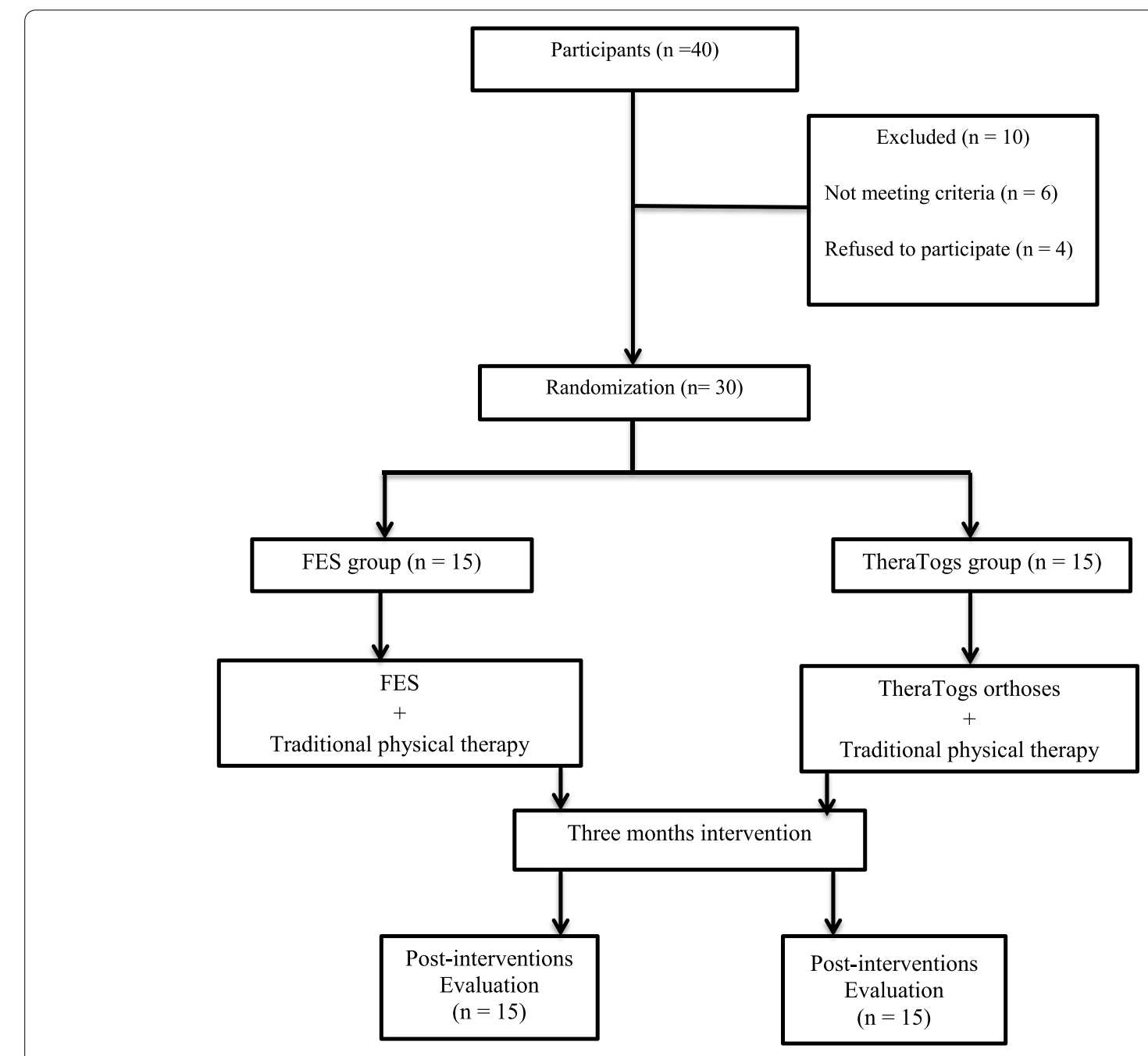

Fig. 1 Flow chart showing the experimental design of the study 
postural stability. It measures the capacity to maintain postural stability on an unsteady surface and is used to test neuromuscular control [23]. A high-resolution color touch screen, support rails, and 12 platform control levels are included in the Biodex. It has a total of 12 levels of stability (12 is more stable and 1 is less stable).

During the assessment, children were asked to maintain a centered position on a slightly unstable surface by shifting their feet until they could easily keep a cursor centered on a screen while standing. The child was then instructed to keep his or her foot in place until the platform was stable. After the foot angles and heel coordinates were entered into the system, the test started. The child was instructed to keep their eyes focused on the visual feedback screen directly in front of them, to keep both arms at their sides without grasping the handrails, and to keep the cursor in the middle of the screen's bull's eye. The test lasted $30 \mathrm{~s}$ and was determined as the average of three tests. The results were printed once the test was completed. The overall stability index, anteriorposterior stability index, and medio-lateral stability index were all included in the results. These results with higher values indicate balance problems [24].

\section{Interventions}

\section{Traditional physical therapy program}

Both groups of children received a traditional physical therapy program that included neuro-developmental treatment for both lower limbs, stretching exercises for tight hip flexors and adductors, knee flexors, and ankle plantar flexors, strengthening exercises for the trunk and both lower limbs, proprioceptive training, balance exercises in all directions from a standing position, and gait training in a closed and open environment, for three consecutive months (1 h/day, 3 days/week) [25].

\section{FES treatment}

The WalkAide stimulator (Innovative Neurotronics, Austin, Texas, USA) was used to administer FES to the children in the FES group. During the swing phase, WalkAide FES has one channel with two electrodes that are adhesively placed on the peroneal nerve to trigger dorsiflexors. The device is powered by a single AA battery and includes a tilt sensor, accelerometer, and inclinometer to detect the rate and angle of the lower leg and initiate stimulation of the peroneal nerve, which generates an action potential that stimulates the dorsiflexors during the swing phase, reducing foot slapping and producing a normal gait pattern.

To stimulate the peroneal nerve before its separation into superficial and deep branches, the active electrode was placed inferior and behind the head of the fibula. The therapist performed small changes to the electrode placement to activate the tibialis anterior muscle more selectively. The electrode sensor was then inserted inside the device cuff to eliminate any bias in electrode position every time the device was worn. To complete the circuit, the passive electrode was inserted over the belly of the tibialis anterior muscle. The intensity of the WalkAide system's asymmetrical biphasic electrical current was gradually increased in order to get the best contraction of the tibialis anterior muscle while remaining within the child's tolerance.

The software was saved on the device once the proper timing was determined, ensuring that the stimulation was continuously delivered and ended at a specific shank angle. The pulse width has been set to a maximum of $300 \mu$ s, and the frequency has been set to a maximum of $33 \mathrm{~Hz}$. With a dial on the WalkAide device, a therapist can adjust the intensity (mA). This device kept track of operation times as well as the total number of stimulations. Electrodes should be changed every $2-3$ weeks for proper care and maximum efficiency. A permanent marker was used to mark the position of the cuff and electrodes on the leg. Children were required to utilize WalkAide for $2 \mathrm{~h}$ per day as massed practice, 3 days per week, for 3 months during FES therapy [26-28].

\section{TheraTogs orthotic treatment}

A sleeveless top vest and two shorts with two thigh cuffs and limb cuffs each make up the TheraTogs strapping system which applied to the children in the TheraTogs group. The TheraTogs suit was worn directly over the skin under the garments, providing breathable, comfortable Latex over the torso and thigh, as well as unrestricted toileting. For infection control and size fitting problems, participants were not allowed to share their TheraTogs with other patients [29].

TheraTogs were applied in two stages: the top vest or hipster fit and the strapping technique. First, the top vest was properly adjusted while the patient was upright, ensuring that there were no constrictions, comfort, or circulation difficulties. This top fitting provides the patient with constant exteroceptive and proprioceptive feeling, allowing the patient to recover core stability and adequate postural orientation, providing the patient with the necessary stability and safety. With the patient in the starting position with the hip in $5^{\circ}$ abduction and external rotation, the hip abduction strapping system was applied. A wide strap was then fastened to the lower back of the affected thigh cuff and drawn up inner to and in front of the thigh, the hip joint, into the sacral region, and attached to the non-affected side's torso. The top two straps supported the top vest in front and back panels, the lower two straps were attached to the thigh cuffs to resist hip adduction while providing vertical trunk 
firmness, and on the outer thigh, the thigh cuff straps were moved closer together, and all straps were modified in length and position to get the desired effect $[19,29]$.

The wearing schedule of TheraTogs for this study was adapted from our previous research on children with CP [20]. TheraTogs orthotic undergarment and strapping system were worn under their regular clothes, so it was neither distracting nor irritating. The participating children wore their TheraTogs as a preparation stage without any exercise program for 1 week before starting the training program, gradually increasing the worn time till reaching $2 \mathrm{~h}$ per day to allow the children to become acclimated to the system [20].

\section{Statistical analysis}

A preliminary power analysis (power $=0.8, \alpha=0.05$, effect size $=0.5$ ) was performed to avoid a type II error, resulting in a sample size of 30 for this study. The sample size was calculated using G Power version 3.1 (HeinrichHeine-Universität, Düsseldorf, Germany).

The results were expressed as mean and standard deviation (SD). Our data were normally distributed which was tested by Shapiro-Wilk test, so the mean values of all measured parameters, comparison of assessments before and immediately after the treatment in each group was performed using paired t-test, whereas the comparison of assessments between both groups before and immediately after treatment was carried out using an unpaired $t$ test. The level of significance was set at alpha $<0.05$. Statistical analysis was performed using SPSS software version 20 (SPSS Inc., IBM, Chicago, IL, USA).

\section{Results}

\section{Flow of participants through the trial}

For this randomized trial, 40 children were screened, 6 children were excluded because they failed to meet the inclusion criteria, and the parents of four children refused to participate in this study. Thirty children (18 boys and 12 girls) with hemiplegic CP participated in this study. They were randomly divided into two groups of equal size ( $n=15$ each). The baseline characteristics of participants are represented in Table 1. The FES and TheraTogs groups were similar in terms of age, weight, height, sex, side of hemiplegia, GMFCS levels, and spasticity grades. Two physical therapists with $\mathrm{PhDs}$ and more than 10-year experience in pediatric rehabilitation supervised the participants' treatment, and each child was trained by the same therapist for all of the sessions.

\section{Effect of interventions}

At baseline, the mean values of gait parameters in the FES and TheraTogs groups were not statistically significant $(P>0.05)$. However, the mean values of gait
Table 1 Demographical and clinical characteristics of the children at baseline

\begin{tabular}{|c|c|c|c|}
\hline \multirow[t]{2}{*}{ Character } & \multirow{2}{*}{$\begin{array}{l}\text { FES group } \\
(n=15) \\
\text { Mean } \pm \text { SD }\end{array}$} & \multirow{2}{*}{$\begin{array}{l}\text { TheraTogs group } \\
(n=15) \\
\text { Mean } \pm \text { SD }\end{array}$} & \multirow[t]{2}{*}{$P$ value } \\
\hline & & & \\
\hline Age (years) & $10.53 \pm 1.24$ & $10.13 \pm 1.25$ & $0.363^{* * *}$ \\
\hline Height (meter) & $1.35 \pm 1.34$ & $1.34 \pm 1.24$ & $0.333^{* * *}$ \\
\hline Weight (kg) & $33.13 \pm 1.73$ & $32.4 \pm 1.92$ & $0.281^{* * *}$ \\
\hline Sex (boy/girl) & $10 / 5$ & $8 / 7$ & $0.473 * *$ \\
\hline Affected side (right/left) & $9 / 6$ & $11 / 4$ & $0.454 * *$ \\
\hline GMFCS level & & & $0.724 * *$ \\
\hline I & 7 & 6 & \\
\hline$\|$ & 8 & 9 & \\
\hline Spasticity grades & & & $0.464^{* * *}$ \\
\hline 1 & 3 & 4 & \\
\hline $1+$ & 6 & 6 & \\
\hline 2 & 6 & 5 & \\
\hline
\end{tabular}

GMFCS Gross Motor Function Classification System

*Significant

**Non-significant

parameters measured at baseline and after treatment were statistically significant $(P<0.05)$. The FES group showed improvements in gait parameters as compared to the TheraTogs group, as shown in Table 2 .

Before treatment, there were no statistically significant differences in mean values of postural stability indices between the FES and TheraTogs groups $(P>0.05)$. The mean values of the postural stability indices obtained from baseline and post-treatment evaluations were statistically significant $(P<0.05)$ in both groups. The FES group improved postural stability significantly more than the TheraTogs group, as shown in Table 3.

\section{Discussion}

The results of this study indicated that a 3-month program of combined FES and traditional physical therapy produced better improvement in gait pattern and postural stability compared with a 3-month program of combined TheraTogs and traditional physical therapy. Significant improvement in both groups in all measuring variables was noted after 3 months of treatment. However, higher improvement was achieved in the FES group in all measuring parameters.

Spasticity often interferes with mobility, especially with walking. Spasticity of the ankle plantar-flexors and weakness and poor selective control of the ankle dorsiflexors can lead to drop foot or true equinus. As a result, children with $\mathrm{CP}$ often have a decreased walking distance and increased incidence of tripping and falling [30]. 
Table 2 Pre and post-treatment mean values of gait parameters within each group and between groups

\begin{tabular}{|c|c|c|c|c|c|c|c|c|c|c|}
\hline \multirow[t]{2}{*}{ Parameters } & \multicolumn{2}{|c|}{ Stride length (m) } & \multicolumn{2}{|c|}{ Cadence (steps/min) } & \multicolumn{2}{|c|}{ Speed (m/s) } & \multicolumn{2}{|c|}{ Cycle time (s) } & \multicolumn{2}{|c|}{ Affected stance (\%) } \\
\hline & Pre & Post & Pre & Post & Pre & Post & Pre & Post & Pre & Post \\
\hline FES group & $0.4 \pm 0.08$ & $0.74 \pm 0.09$ & $131.3 \pm 4.75$ & $119.9 \pm 5.11$ & $0.47 \pm 0.07$ & $0.75 \pm 0.83$ & $0.4 \pm 0.07$ & $0.65 \pm 0.05$ & $46.5 \pm 1.69$ & $55.9 \pm 1.67$ \\
\hline TheraTogs group & $0.38 \pm 0.78$ & $0.5 \pm 0.07$ & $130 \pm 3.96$ & $125 \pm 4.23$ & $0.47 \pm 0.08$ & $0.6 \pm 0.07$ & $0.37 \pm 0.07$ & $0.49 \pm 0.07$ & $45.33 \pm 1.8$ & $50.47 \pm 1.85$ \\
\hline Tvalue & 0.68 & 7.48 & 0.84 & -2.96 & -0.24 & 5.28 & 1.00 & 7.13 & 1.89 & 8.51 \\
\hline Pvalue & $0.51^{* *}$ & $0.001^{*}$ & $0.41^{* *}$ & $0.006^{*}$ & $0.81^{* *}$ & $0.001^{*}$ & $0.33^{* *}$ & $0.001^{*}$ & $0.07^{* *}$ & $0.001^{*}$ \\
\hline
\end{tabular}

Level of significance at $P<0.05$

*Significant

**Non-significant

Table 3 Pre- and post-treatment mean values of postural stability indices within each group and between groups

\begin{tabular}{|c|c|c|c|c|c|}
\hline \multirow[t]{2}{*}{ Parameters } & & \multirow{2}{*}{$\begin{array}{l}\text { FES group } \\
\text { Mean } \pm \text { SD }\end{array}$} & \multirow{2}{*}{$\begin{array}{l}\text { TheraTogs group } \\
\text { Mean } \pm \text { SD }\end{array}$} & \multirow[t]{2}{*}{$T$ value } & \multirow[t]{2}{*}{$P$ value } \\
\hline & & & & & \\
\hline \multirow[t]{4}{*}{ Overall stability index } & Pre & $3.37 \pm 0.21$ & $3.28 \pm 0.16$ & 1.32 & $0.198^{* *}$ \\
\hline & Post & $2.25 \pm 0.16$ & $2.75 \pm 0.15$ & -8.57 & $<0.001^{*}$ \\
\hline & Tvalue & 27.67 & 12.91 & & \\
\hline & Pvalue & $<0.001^{*}$ & $<0.001^{*}$ & & \\
\hline \multirow[t]{4}{*}{ Antero-posterior stability index } & Pre & $2.85 \pm 0.16$ & $2.78 \pm 0.14$ & 1.18 & $0.248^{* *}$ \\
\hline & Post & $1.8 \pm 0.15$ & $2.26 \pm 0.19$ & -7.04 & $<0.001^{*}$ \\
\hline & Tvalue & 34.36 & 16.48 & & \\
\hline & Pvalue & $<0.001^{*}$ & $<0.001^{*}$ & & \\
\hline \multirow[t]{4}{*}{ Medio-lateral stability index } & Pre & $2.32 \pm 0.29$ & $2.24 \pm 0.28$ & 0.82 & $0.419^{* *}$ \\
\hline & Post & $1.65 \pm 0.16$ & $2.01 \pm 0.18$ & -5.51 & $<0.001^{*}$ \\
\hline & Tvalue & 11.75 & 5.40 & & \\
\hline & Pvalue & $<0.001^{*}$ & $<0.001^{*}$ & & \\
\hline
\end{tabular}

Level of significance at $P<0.05$

*Significant

**Non-significant

The mechanism for gait improvement after FES is not well understood, but a possible hypothesis involves reciprocal inhibition, proposing that FES reduces muscle contraction at the ankle joint by addressing impaired reciprocal inhibition. FES produces stimulation of the tibialis anterior muscle, which would cause inhibition of the gastrocnemius muscle, thereby enabling better prepositioning of the foot for the stance phase of gait. This reciprocal inhibition coupled with increased awareness caused by the stimulation might also account for the observed improvements in selective motor control of the ankle joint [31].

The positive effect on walking recovery in these children is due to stimulating the peroneal nerve, which actively dorsiflexes the ankle and strengthens the muscles. At high levels, common peroneal nerve stimulation can produce hip and knee flexion, and it has also been claimed to reduce or counteract spasticity $[18,32]$. This may lead to a global improvement of walking function and, maybe, a lower cost of oxygen consumption. Thus, children during therapy may walk more and better, performing more steps with less overexertion [33].

The improvement of postural stability in the FES group could be due to regaining normal muscle contraction sequences, which had been affected in children with CP, starting with the activation of the anterior tibial group, followed by the proximal lower limb muscles, and finally the trunk muscles. Furthermore, the FES caused nerve and muscle stimulation to be repeated and continuous, resulting in an increase in synaptic transmission of intact neural fibers, the advancement of new synaptic pathways, and the support of linking alignments in the nervous system [34].

Mäenpää and colleagues [35] described children with spastic hemiplegia or diplegia and weak or absent active ankle dorsiflexion who received electrical stimulation of the tibialis anterior muscle during ordinary scheduled physical therapy sessions for 1 month. In that study, 
electrical stimulation at the sensory level combined with physical therapy improved active and passive motions of the ankle and foot, and the improvement persisted for months after the termination of electrical stimulation therapy.

TheraTogs strapping system used in this study increased proprioceptive stimulation and decreased muscle length, promoting the action of the hip abductors and extensors and allowing for normal firing and recruitment mechanisms of these muscles, resulting in increased force generation and improved body static and dynamic balance. Furthermore, using the TheraTogs strapping system to position the affected limb in external rotation and abduction caused reflex inhibition of the spastic hip internal rotators and adductor muscles, facilitating normal antagonistic muscular activation [36].

The findings of this study are similar to those of Sherief et al. [37], they found that combining FES with traditional physical therapy treatment improved balance and functional abilities in hemiplegic CP. Pool et al. [14], have also demonstrated that short-term daily community FES is a beneficial activity-based treatment with orthotics and therapeutic effects. Up to 6 weeks after therapy, improvements in community mobility, balance, and spasticity can be shown. This indicates that FES can be used to treat children with $\mathrm{CP}$ and equinus gait patterns during everyday walking activities.

This study's findings are similar to those of Eid et al. [38], and they examined the impact of FES versus hinged AFO on gait performance in children with hemiplegic $\mathrm{CP}$. Both the FES and the hinged AFO have been shown to enhance gait characteristics such as stride length, gait velocity, and ankle dorsiflexion angle at initial contact and mid-swing. FES, on the other hand, is more effective at increasing ankle dorsiflexion angle in the middle of the gait cycle.

Prenton et al. [39], disagree with the findings of this study, suggesting that, contrary to belief, AFO show the same positive combined-orthotic effects as FES on key walking measures for stroke-related foot drop. However, additional high-quality, long-term RCTs are needed. These should concentrate on determining the mechanisms of action, as well as whether improvements in impairment translate into improved function, as well as detailed reporting of the devices utilized across diagnosis.

However, there are some limitations to this study, including the small sample size, which limits the generalization of the findings; lack of a control group that received the traditional therapy only; the lack of participants with different types of CP; and the lack of follow-up the children after the cessation of interventions. The current study's findings are promising, but future research with a larger number of children with $\mathrm{CP}$ would provide results that could be more easily generalized. It was also important to search into the long-term effects of FES and TheraTogs on functional activity. Future research on the effects of FES and TheraTogs, as well as their involvement in enhancing muscle strength, bone mineral density, and energy expenditure in children with $\mathrm{CP}$, could help clinicians make better decisions.

\section{Conclusions}

FES is significantly more effective than TheraTogs strapping systems in improving gait pattern and postural stability in children with hemiplegic $\mathrm{CP}$, according to the findings of this study.

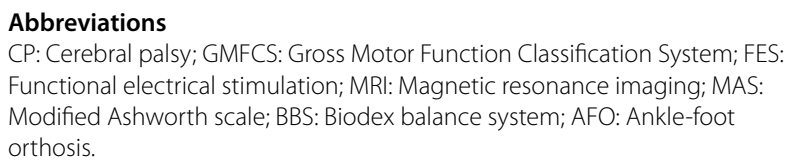

\section{Acknowledgements}

The authors would like to thank the Deanship of Scientific Research at Umm Al-Qura University for supporting this work by Grant Code:19-MED-1-01-0003.

\section{Authors' contributions}

SME and EMA conceived and designed the study and conducted the data collection. SME and EMA analyzed and interpreted the data in addition to reviewing the final results. SME and EMA provided logistical support and wrote the initial and final drafts of the article. SME and EMA are responsible for the findings and have critically reviewed and approved the final draft of the article. All authors have read and approved the manuscript.

\section{Funding}

The authors confirmed that there is no financial support.

\section{Availability of data and materials}

The datasets generated during and/or analyzed during the current study are available from the corresponding author on reasonable request.

\section{Declarations}

\section{Ethics approval and consent to participate}

The study was approved by the Biomedical Research Ethics Committee, Umm Al Qura University. Approval No. (HAPO-02-K-012-2020-12-516). Parents of all participants signed a written informed consent before starting the study.

\section{Consent for publication}

N/A

\section{Competing interests}

The authors declare that they have no competing interests.

Received: 20 September 2021 Accepted: 1 November 2021

Published online: 28 December 2021

\section{References}

1. Allen J, Zareen Z, Doyle S, Whitla L, Afzal Z, Stack M, et al. Multi-organ dysfunction in cerebral palsy. Front Pediatr. 2021;9:668544.

2. Stavsky M, Mor O, Mastrolia SA, Greenbaum S, Than NG, Erez O. Cerebral palsy-trends in epidemiology and recent development in prenatal mechanisms of disease, treatment, and prevention. Front Pediatr. 2017;5:21. 
3. Reid SM, Carlin JB, Reddihough DS. Distribution of motor types in cerebral palsy: how do registry data compare? Dev Med Child Neurol. 2011;53(3):233-8

4. Prosser LA, Curatalo LA, Alter KE, Damiano DL. Acceptability and potential effectiveness of a foot drop stimulator in children and adolescents with cerebral palsy. Dev Med Child Neurol. 2012;54(11):1044-9.

5. Pinto TPS, Fonseca ST, Gonçalves RV, Souza TR, Vaz DV, Silva PLP, et al. Mechanisms contributing to gait speed and metabolic cost in children with unilateral cerebral palsy. Braz J Phys Ther. 2018;22(1):42-8.

6. Wilson NC, Mackey AH, Stott NS. How does the functional mobility scale relate to capacity-based measures of walking ability in children and youth with cerebral palsy? Phys Occup Ther Pediatr. 2014;34:185-96.

7. Werner D. Disabled village children, a guide for community health workers, rehabilitation workers and families. USA Hesperian Found. 2018:301-18.

8. O'Brien SM, Lichtwark GA, Carroll TJ, Barber LA. Impact of lower limb active movement training in individuals with spastic type cerebral palsy on neuromuscular control outcomes: a systematic review. Front Neurol. 2020;11:581892.

9. Liu XC, Embrey D, Tassone C, Klingbeil F, Marquez-Barrientos C, Brandsma $B$, et al. Foot and ankle joint movements inside orthoses for children with spastic CP. J Orthop Res. 2014;32(4):531-6.

10. Dursun N, Bonikowski M, Dabrowski E, Matthews D, Gormley M, Tilton $A$, et al. Efficacy of repeat AbobotulinumtoxinA (Dysport ${ }^{\circledR}$ ) injections in improving gait in children with spastic cerebral palsy. Dev Neurorehabil. 2020;23(6):368-74.

11. Altschuck N, Bauer C, Nehring I, Böhm H, Jakobeit M, Schröder AS, et al. Efficacy of pre- fabricated carbon-composite ankle foot orthoses for children with unilateral spastic cerebral palsy exhibiting a drop foot pattern. J Pediatr Rehabil Med. 2019;12(2):171-80.

12. Aboutorabi A, Arazpour M, Ahmadi Bani M, Saeedi H, Head JS. Efficacy of ankle foot orthoses types on walking in children with cerebral palsy: a systematic review. Ann Phys Rehabil Med. 2017;60(6):393-402.

13. Desloovere K, Molenaers G, Van Gestel L, Huenaerts C, Van Campenhout A, Callewaert B, et al. How can push-off be preserved during use of an ankle foot orthosis in children with hemiplegia? A prospective controlled study. Gait Posture. 2006;24(2):142-51.

14. Pool D, Valentine J, Bear N, Donnelly CJ, Elliott C, Stannage K. The orthotic and therapeutic effects following daily community applied functional electrical stimulation in children with unilateral spastic cerebral palsy: a randomized controlled trial. BMC Pediatr. 2015;15:154.

15. Damiano DL, Prosser LA, Curatalo LA, Alter KE. Muscle plasticity and ankle control after repetitive use of a functional electrical stimulation device for foot drop in cerebral palsy. Neurorehabil Neural Repair. 2013;27:200-7.

16. Karabay I, Öztürk GT, Malas FÜ, Kara M, TiftikT, Ersöz M, et al. Short-term effects of neuromuscular electrical stimulation on muscle architecture of the tibialis anterior and gastrocnemius in children with cerebral palsy: preliminary results of a prospective controlled study. Am J Phys Med Rehabil. 2015;94(9):728-33.

17. Zahradka N, Behboodi A, Sansare A, Lee SCK. Evaluation of individualized functional electrical stimulation-induced acute changes during walking: a case series in children with cerebral palsy. Sensors (Basel). 2021:21(13):4452

18. Karunakaran KK, Pilkar R, Ehrenberg N, Bentley KS, Cheng J, Nolan KJ. Kinematic and functional gait changes after the utilization of a foot drop stimulator in pediatrics. Front Neurosci. 2019;13:732.

19. Ehlert R, Manfio EF, Heidrich RO, Goldani R. Cerebral palsy: influence of TheraTogs ${ }^{\circledR}$ on gait, posture and in functional performance. Fisioter Mov. 2017;30(2):307-17.

20. El-Shamy S, Abd El Kafy E. Efficacy of axial TheraTogs on gait pattern in children with dyskinetic cerebral palsy: a randomized controlled trial. Bull Fac Phys Ther. 2021;26:12.

21. Abd El-Kafy EM, El-Basatiny HM. Effect of postural balance training on gait parameters in children with cerebral palsy. Am J Phys Med Rehabil. 2014;93:938-47.

22. El-Shamy SM, Eid MA, El-Banna MF. Effect of extracorporeal shock wave therapy on gait pattern in hemiplegic cerebral palsy: a randomized controlled trial. Am J Phys Med Rehabil. 2014;93:1065-72.

23. Dawson N, Dzurino D, Karleskint M, Tucker J. Examining the reliability, correlation, and validity of commonly used assessment tools to measure balance. Health Sci Rep. 2018:1(12):1-8.
24. El-Shamy SM. Effects of antigravity treadmill training on gait, balance, and fall risk in children with diplegic cerebral palsy. Am J Phys Med Rehabil. 2017:96(11):809-15.

25. Levitt $S$ and Addison A. Treatment of Cerebral Palsy and Motor Delay, $6^{\text {th }}$ Edition. Hoboken, NJ: Wiley-Blackwell, 2019; P: 157-308.

26. El-Shamy SM, Abdelaal AAM. WalkAide efficacy on gait and energy expenditure in children with hemiplegic cerebral palsy: a randomized controlled trial. Am J Phys Med Rehabil. 2016;95:629-38.

27. Bethoux F, Rogers H, Nolan K, Abrams G, Annaswamy T, Brandstater M, et al. Long-term follow-up to a randomized controlled trial comparing peroneal nerve functional electrical stimulation to an ankle foot orthosis for patients with chronic stroke. Neurorehabil Neural Repair. 2015;29:911-22.

28. Pool D, Blackmore AM, Bear N, Valentine J. Effects of short-term daily community walk aide use on children with unilateral spastic cerebral palsy. Pediatr Phys Ther. 2014;26(3):308-17.

29. Flanagan A, Krzak J, Peer M, Johnson P, Urban M. Evaluation of short-term intensive orthotic garment use in children who have cerebral palsy. Pediatr Phys Ther. 2009;21(2):201-4.

30. Choi JY, Park ES, Park D, Rha DW. Dynamic spasticity determines hamstring length and knee flexion angle during gait in children with spastic cerebral palsy. Gait Posture. 2018;64:255-9.

31. Moll I, Vles JSH, Soudant DLHM, Witlox AMA, Staal HM, Speth LAWM, et al. Functional electrical stimulation of the ankle dorsiflexors during walking in spastic cerebral palsy: a systematic review. Dev Med Child Neurol. 2017;59(12):1230-6.

32. Malešević J, Konstantinović L, Bijelić G, Malešević N. Smart protocols for physical therapy of foot drop based on functional electrical stimulation: a case study. Healthcare (Basel). 2021;9(5):502.

33. Mooney JA, Rose J. A scoping review of neuromuscular electrical stimulation to improve gait in cerebral palsy: the arc of progress and future strategies. Front Neurol. 2019;10:887.

34. Moon JH, Cho HY, Hahm SC. Influence of electrotherapy with taskoriented training on spasticity, hand function, upper limb function, and activities of daily living in patients with subacute stroke: a doubleblinded, randomized, controlled trial. Healthcare (Basel). 2021;9(8):987.

35. Mäenpää H, Jaakkola R, Sandström M, von Wendt L. Effect of sensorylevel electrical stimulation of the tibialis anterior muscle during physical therapy on active dorsiflexion of the ankle of children with cerebral palsy. Pediatr Phys Ther. 2004;16:39-44.

36. El Fiky A, Elsodany A, Abd E-KE. Effect of TheraTogs orthotic undergarment on postural balance control, risk of fall, and walking abilities in Saudi individuals with chronic stroke. Jokull Journal. 2016;66(5):23-35.

37. Sherief A, Elnegamy T, Seyam M, Abdel GM. Can functional electrical stimulation affect equilibrium and motor functions in spastic hemiparetic cerebral palsy? A randomized controlled study. Egy J Phys Ther. 2020;4(1):20-4.

38. Eid M, Mohamed R, Aly S. Functional electrical stimulation versus hinged ankle foot orthosis in improving gait parameters in hemiplegic cerebral palsy. Bull Fac Ph Th Cairo Univ. 2014;19(2):1-16.

39. Prenton $\mathrm{S}$, Hollands $\mathrm{KL}$, Kenney LP. Functional electrical stimulation versus ankle foot orthoses for foot-drop: a meta-analysis of orthotic effects. J Rehabil Med. 2016;48(8):646-56.

\section{Publisher's Note}

Springer Nature remains neutral with regard to jurisdictional claims in published maps and institutional affiliations. 